\title{
AS FORMAÇÕES EM BOLAS ARGENTICAS DO SISTEMA NERVOSO SIMPÁTICO
}

\author{
José Fernandez *
}

Em histologia normal e patológica do sistema nervoso vegetativo existem dúvidas que suscitam revisões. Um delas refere-se à significação das bolas argênticas observadas em gânglios simpáticos impregnados pelos métodos da prata; apesar dos importantes trabalhos de Lasowsky, Lawrentiew e Lasowsky e de Herzog, o problema ainda não foi solucionado. Para alguns essas formações são normais no sistema vegetativo, outros afirmam que são produções patológicas; para um terceiro grupo de pesquisadores elas são normais, porém aumentam numèricamente nos casos patológicos.

Cajal 4, em 1906, parece ter sido o primeiro a descrever as bolas argênticas, afirmando que elas seriam o resultado de processos regenerativos, dentro de certos limites fisiológicos, em individuos com idade avançada. Em 1909, Marinesco ${ }^{27}$ esiudou as alterações produzidas nos elementos nervosos pa: compressão e descreveu, nos gânglios cervicais, formações em bolas argênticas. Em 1914, Achúcarro ${ }^{1}$, estudando as alterações do gânglio cervical superior, descreveu finas fibras que terminavam $\mathrm{\epsilon m}$ bolas volumosas, admitindo que as de maiores dimensões, como as descritas por Cajal nos velhos, seriam de origem patológica. Castro ${ }^{5}$, em 1922, estudando os gânglios sensitivos, descreveu bolas argênticas em neurônios normais e patológicos, observando, pela primeira vez, formaçōes subcapsulares em rosário; em 1923, estudando gânglios simpáticos, descreveu ${ }^{6}$, em casos que considerou normais, a presença de bolas argênticas, em pequeno número e de pequenas dimensōes, bem visiveis nas terminações dos dendritos. Schaffer ${ }^{30}$, em 1923, encontrou, em casos de doença de Tay-Sachs, formaçōes em bolas argênticas que considerou como resultantes de irritações patológicas.

Importantes são os trabalhos de Lawrentiew e Lasowsky 26 e de Castro $:, 8,9$, que estudaram os processos de degeneração nos gânglios simpáticos da cadeia lateral: Castro descreveu formaçōes em bolas argênticas nas terminaçōes das fibras pré-ganglionares; Lawrentiew seccionou fibras pré-ganglionares, encontrando formações $\mathrm{em}$ bolas argênticas que descreveu como produtos degenerativos.

Lasowsky ${ }^{24}$ descreveu, nos gânglios intracardíacos, em portadores de arteriosclerose e suas complicações, bolas argênticas na parte terminal dos pro-

* Assistente da Faculdade de Medicina da Universidade da Bahia e da Escola Baiana de Medicina e Saúde Pública. Patologista da Fundação Hospitalar Octavio Mangabeira. 
longamentos curtos das células nervosas. Para êste autor existe relação direta entre o grau de alteração dos gânglios intracardiacos e a doença coronária: a destruição, por anóxia, de fibras do miocárdio, determinaria alteraçōes das terminaçôes dos neurônios que inervam o território lesado, e o axônio entraria em degeneração, com a formação de bolas argênticas. Melo ${ }^{28}$. em indivíduos de tôdas as idades e com maior freqüência em casos de aterosclerose e em alguns de tuberculose, descreveu formações semelhantes às descritas por Cajal, admitindo tratar-se de formaçōes patológicas.

Fedorow ${ }^{12}$ estudou o fenômeno de degeneração walleriana nos neurônios simpáticos, descrevendo granulaçōes que dividiu em dois tipos conforme houvesse ou não impregnação pela prata. Segundo Fedorow e Matwejewa 13, 14, os processos degenerativos, após a secção das fibras pré-ganglionares, são representados por uma argentofilia mais intensa nas malhas dos discos terminais das fibras seccionadas, seguindo-se vacuolização com aparecimento de grânulos mais ou menos volumosos. Lawrentiew e Filatowa ${ }^{2 \cdot i}$, estudando a histopatologia das terminações nervosas na laringite tuberculosa, relacionaram as alterações das terminações nervosas com as que se podem verificar na própria célula nervosa, afirmando ser perfeitamente possivel que o agente nocivo atue em primeiro lugar sôbre o corpo do neurônio.

Estudos mais recentes sôbre a degeneração e regeneraçāo das fibras do simpático foram feitas por Bullón Ramírez ${ }^{2}$ no reto e por Bullón Ramírez e Lamas López ${ }^{3}$ no esôfago e no estómago: nos trabalhos dêstes autores foram assinaladas fibras pré-terminais e terminais com engrossamentos em forma de bolas argênticas. Herzog ${ }^{19}$, em 1942, em 115 casos humanos, verificou a presença de bolas argênticas nos gânglios do simpático e do vago, tanto em indivíduos normais como em casos patológicos, em tôdas as idades, desde prematuros até individuos de 107 anos. Herzog conclui que as bolas argênticas podem ser observadas desde os primeiros anos de idade, nas terminações de fibras nervosas finas e grossas, com localização intra e extracapsular; elas aumentam com a idade e "se tiene la impresión que, en ciertas ocasiones, probablemente por condiciones patológicas, puede aumentar el número de estas formaciones pero sin guardar estrictas relaciones con determinadas enfermedades". Entretanto, em trabalho mais recente, Herzog ${ }^{26}$ afirma que as bolas argênticas constituem produto patológico.

\section{MATERIAL, MÉTODOS E RESULTADOS}

Para o presente trabalho, examinamos gânglios simpáticos de 40 casos patológicos: tuberculose pulmonar (9), tromboangeíte obliterante (8), úlcera trófica (8), arteriosclerose (6), síndrome pós-flebite (4), moléstia de Raynaud (2), asma brônquica (1), sindrome ombro-mão (1), hipertensão essencial (1). Examinamos também 40 gânglios tidos como normais: gânglio cervical superior (8), gânglio estrelado (8), gânglios torácicos (8), gânglios lombares (8), gânglio semilunar (8). A fixação foi feita em formol neutro, formol- 
sonifeno e pela mistura A.F.A. As impregnações foram obtidás pelas variantes de Cajal, pelos métodos de Castro, Arteta, Gros, Bielschowsky e Agduhr. Tôdas as peças pertenciam a individuos adultos, entre 20 a 50 anos de idade.

Os resultados obtidos com os vários métodos de impregnação foram excelentes. Procuramos as formações em bolas argênticas nás terminações nervosas e também no final dos dendritos; quando eram vistas, examinávamos cuidadosamente o neurônio correspondente para estudar as reações porventura existentes; notamos sempre alguma alteração no neurônio, às vêzes de caráter leve (maior afinidade pelos sais de prata, condensação das neurofibrilas), outras vèzes grave (hiperplasia e hipertrofia dos dendritos, degeneração retrátil). Como fato freqüente, notamos que o prolongamento que apresentava a formação em bola argêntica, se encontrava hipertrofiado.

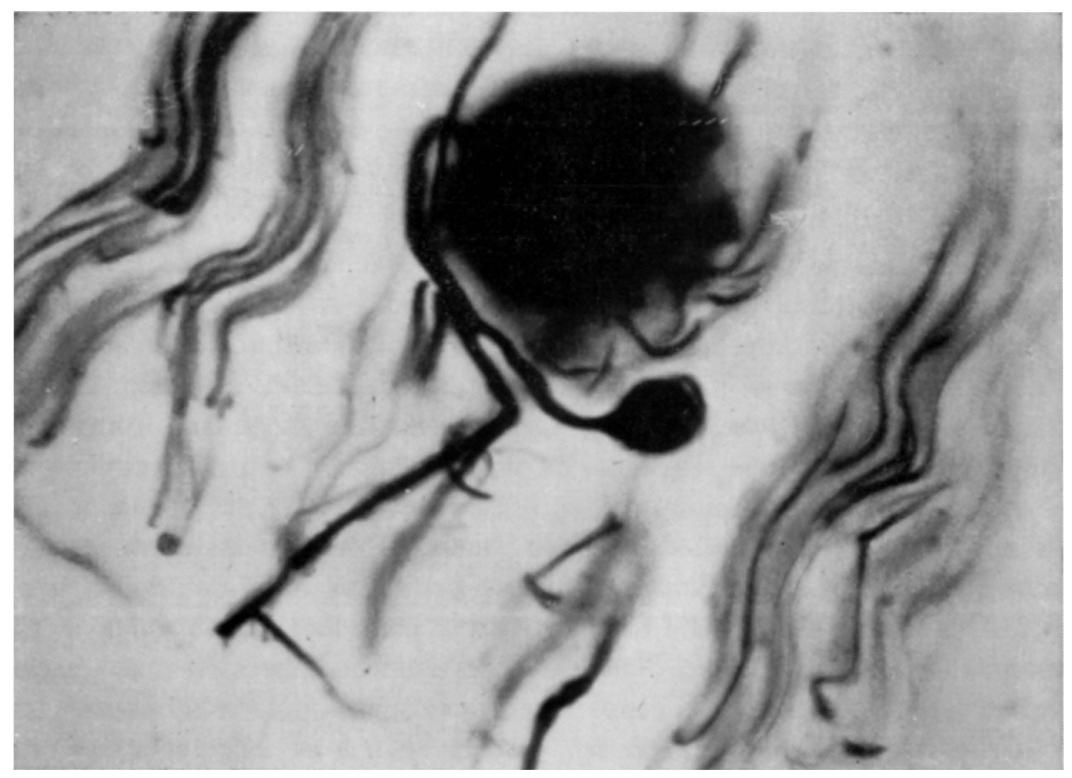

Fig. 1 - Método de Gros (450x). Neurônio que apresenta uin dendrito com formaçio em bola argêntica, polendo notar-se, na periferia desta, uma parte clara com pálidas ramificações em forma de rêde.

Gros' method (450x). Neuron showing dendrite with an argentic ball formation in which periphery a light part can bo noticed with slight netform ramifications.

As bolas argênticas aparecem como formaçōes esféricas muito bem impregnadas com os sais de prata, sem estrutura especial: quando muito, pudemos observar, na parte mais periférica de algumas dessas formaçōes, uma coloração mais pálida, deixando ver finas ramificações algo semelhantes às observadas no citoplasma dos neurônios (fig. 1). Nota-se freqüentemente 
que o ponto de passagem da bola argêntica para o prolongamento (fibra ou dendrito) é constituído por um colo afunilado; entretanto, quando o prolongamento se encontra intensamente hipertrofiado, tal afunilamento não aparece, tornando-se a bola argêntica (fig. 2). Em alguns casos verificamos que a existência de bolas argênticas se associava à presença de fibras nervosas volumosas, intensamente hipertrofiadas, tortuosas e fortemente impregnadas pelos sais de prata; mesmo quando a preparação era impregnada levemente, as bolas argênticas $e$ as fibras hipertrofiadas e tortuosas se encontravam intensamente impregnadas pela prata (fig. 3 ).

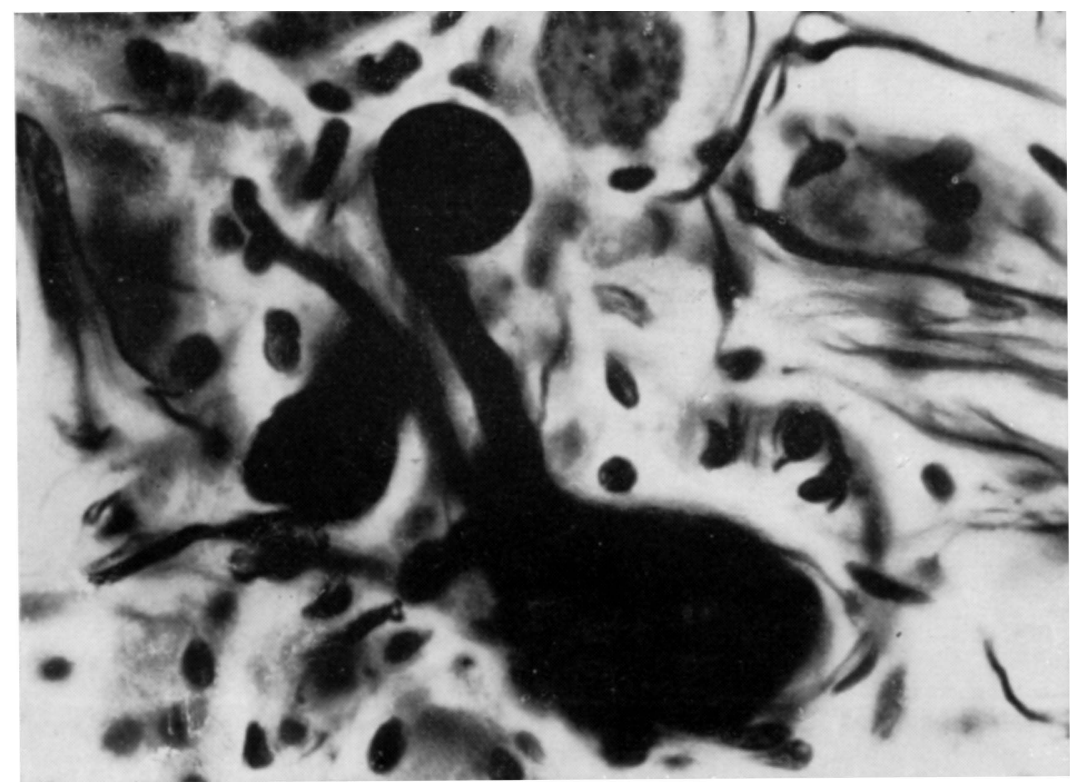

Fig. 2 - Método de Gros (45cx). Arteriosclerose. Neurônio intensamente impregnado, com dentrito exageradanente hipertrofiado, que termina po, uma formaçio em clava.

Gros' method $(45 \mathrm{Cx})$. Arteriosclerosis. Intensely impregnated neuron with hypertrophyed dentrite ending in a spherical claval formation.

A degeneração retrátil dos neurônios foi notada em grande proporção de casos em que existem bolas argênticas (fig. 4); em um estágio ulterior, o neurônio pode se apresentar como simples mancha cheia de pequenos pontos negros, sem estrutura alguma, semelhante ao que foi descrito por Orellana ${ }^{29}$ com o nome de "pigmento negro argentófilo". Nestas circunstâncias observamos a presença de várias bolas argênticas, com a disposição descrita por Castro ${ }^{\circ}$ com o nome de "arrozariada", porém de caráter mais intenso, aparentemente sem continuação, cercando o neurônio, e com tamanho quase 
igual ao do corpo dêste (fig. 5). Outras vêzes o neurônio evolui para uma degeneração retrátil mais intensa, sem apresentar pigmentos; há coagulação das neurofibrilas e hipertrofia intensa nos poucos dendritos visiveis, com diferenciação bem evidente entre a impregnação da bola argêntica e a do neurônio apergaminhado (fig. 6).

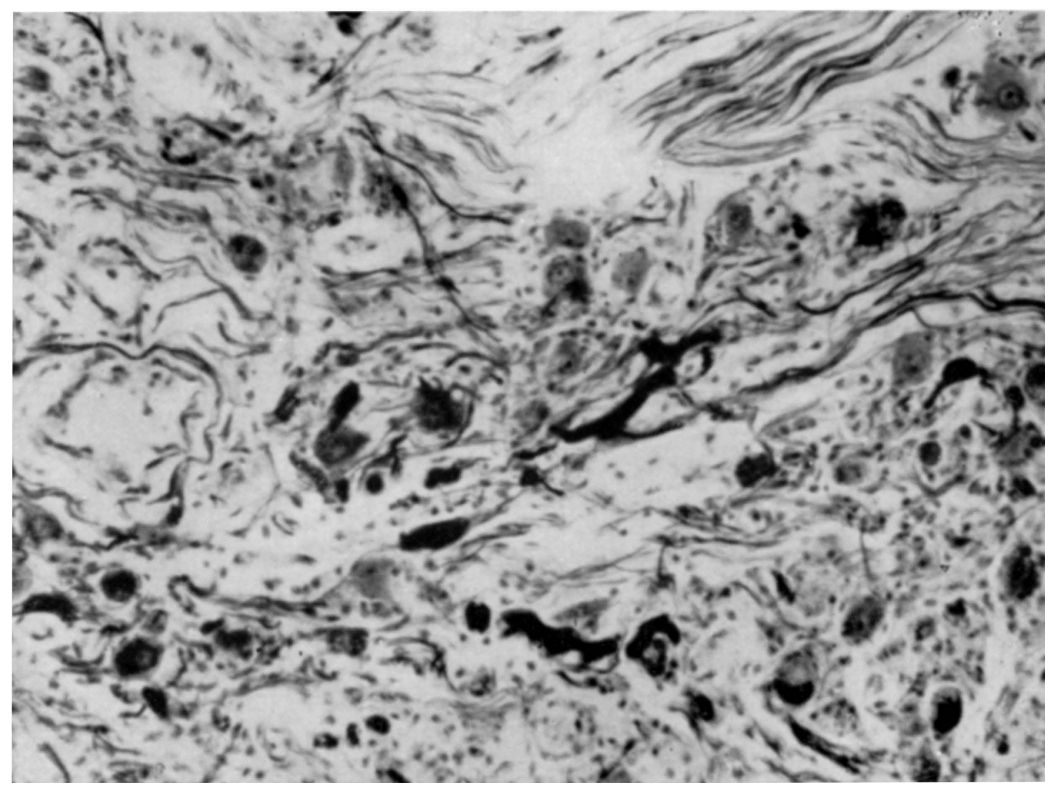

Fig. 3 - Método de Castro (450x). Tuberculose. Fibras intensamente hipertrofiadas e fortemente impregnadas.

Castro's method (450x). Tuberculosis. Fibers hypertrophyed and strongly impregnated.

As bolas argênticas podem ser intra e extracapsulares. As intracapsulares mostram a relação existente entre elas e o neurônio, podendo-se observar, freqüentemente, que o elemento celular sofre uma retração na parte do citoplasma vizinho à bola, formando uma escavação que lhe serve de ninho (figs. 7 e 8). Em um de nossos casos (fig. 2) tivemos a oportunidade de verificar a presença de volumosa formação argêntica, semelhante à descrita por Herzog ${ }^{22}$ em um caso de câncer do esôfago associado a arteriosclerose generalizada.

De modo geral, dividimos nossos resultados em dois grupos: os observados nos casos patológicos e aquêles vistos em gânglios tidos como normais. As formaçōes em bolas argênticas são muito mais freqüentes nos casos patológicos; nos casos tidos como normais, elas são encontradas em percentagem muito pequena e sempre de forma isolada. 
Não pudemos verificar a existência de relação de concordância entre as várias enfermidades e a produção das bolas argênticas; em alguns casos verificamos a presença de numerosas bolas argênticas, ao passo que, em outros casos da mesma doença, assinalamos sua raridade ou mesmo ausência. Os casos de doenças vasculares periféricas foram os que forneceram maiores oportunidades para estudar as formaçōes em questão, oferecendo, também. as melhores figuras.

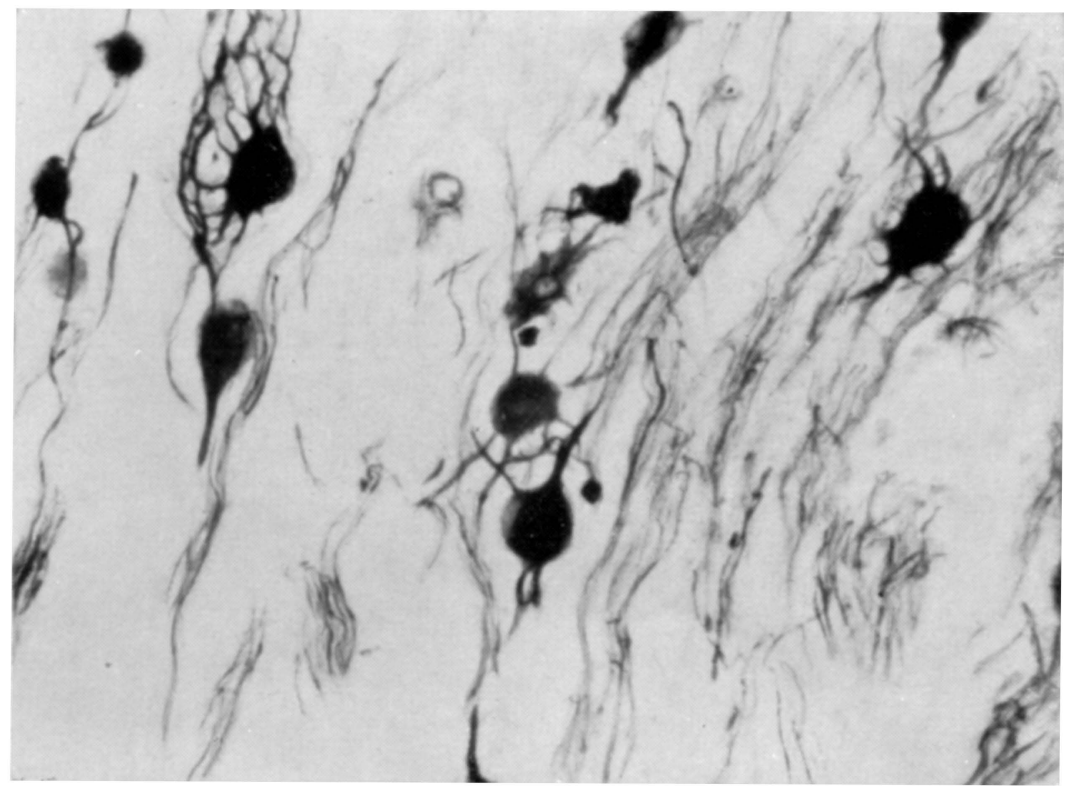

Fig. 4 - Método de Castro. Tromboangeqte obliterante. No centro da microfotografia, duas formações em bolas argênticas diretamente relacionadas com neurônios que apresentam alierações neurofibrilares.

Castro's method. Obliterating tromboangeitis. In the central part of the picture two argentic balls jormations can be seen, directly related to neurons presenting neurofibrillary alterations.

\section{COMENTARIOS}

Desde que iniciamos os estudos sôbre o sistema nervoso vegetativo periférico tivemos oportunidade de observar a presença das bolas argênticas de Cajal em variados casos patológicos 1j,16,17. Resolvemos, agora, estudar melhor o assunto.

As bolas argênticas encontradas em casos tidos como normais, são, na realidade, formaçōes patológicas. Devemos ter presente que órgão normal não é aquêle no qual tôdas as células são normais, senão aquêle no qual a maioria dos elementos tem êste requisito. Em publicação anterior ${ }^{16}$, referi- 
mos que em um gânglio simpático normal, podemos encontrar até $24 \%$ de neurônios patológicos. As alterações observadas nesta percentagem, são do tipo proliferativo ou degenerativo, podendo ser vistas hiperplasias ou hipertrcfias dos dendritos, degeneração retrátil, produção de bolas argênticas. A percentagem de elementos que apresentam alterações, nos gânglios normais, aumenta com a idade; como conseqüência disto, verificamos também aumento das bolas argênticas nos indivíduos idosos, fato êste já relatado por Cajai e confirmado por Herzog.

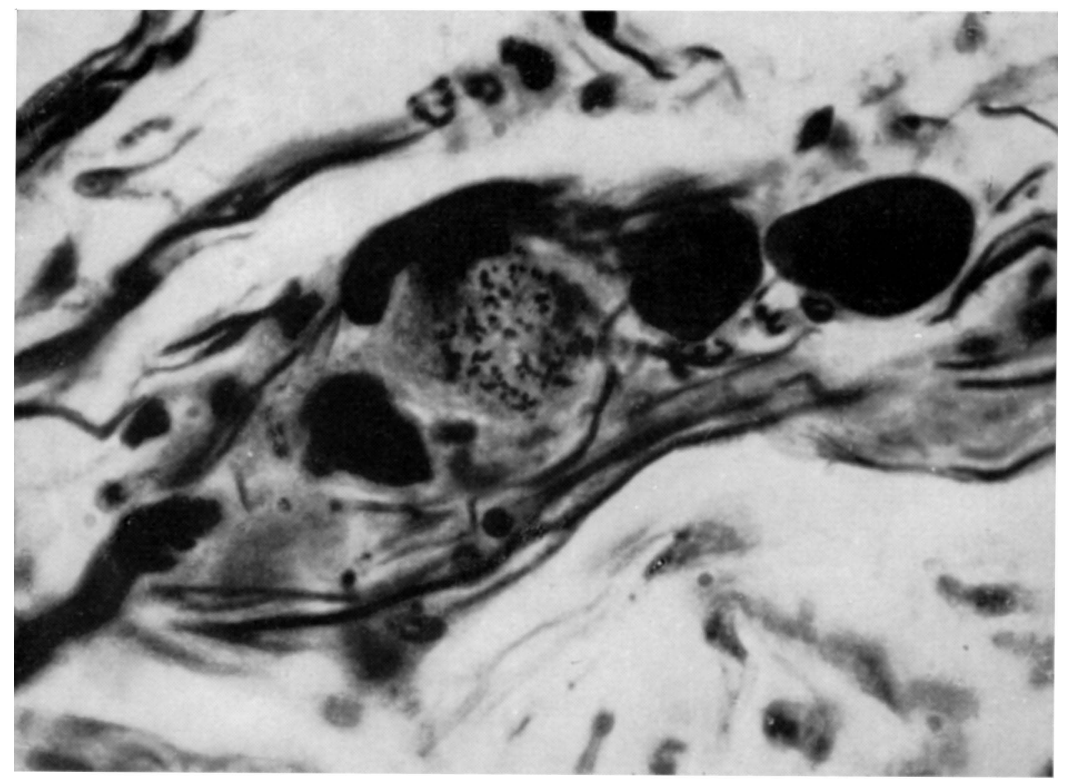

Fig. 5 - Método de Gros (450x). Tıberculose. Neurònio com intensa pigmentação, notundo-se, em volta, formaçòes em rosário.

Gros' method (450x). Tuberculosis. Neuron with intense pigmentation: rosary-like formations can be noticed urount! it.

Segundo as observações de Herzog ${ }^{21}$, è nos casos de transtornos circulatórios periféricos que se observam alterações produtivas nas células nervosas, principalmente hiperplasia e formações em bolas argênticas, faltando, por completo, os processos degenerativos. Nos nossos casos de distúrbios circulatórios periféricos (tromboangeite obliterante, úlcera trófica, moléstia de Raynaud, arteriosclerose), foi notada a predominância dos chamados processos proliferativos, principalmente a hipertrofia e hiperplasia dendrítica; estas alterações foram vistas na totalidade de nossos casos, se bem que as melhores figuras sejam dadas pelos de distúrbios circulatórios, levando à conclusão de que o sistema vegetativo periférico possui poucas modalidades de reação. As bolas argênticas são encontradas sem especificidade em relação a qualquer tipo de enfermidade. Em um de nossos casos de tuberculose (fig. 5), 
surpreendemos um neurônio cujo soma celular estava completamente substituido por pigmentos de tipo melânico; em volta dêste elemento havia numerosas bolas argênticas, aparentemente sem continuação umas com as outras, lembrando as figuras descritas por Castro com o nome de "arrosariadas". Emhart ${ }^{11}$ também se refere à presença de bolas argênticas em casos de tuberculose pulmonar e laringea.

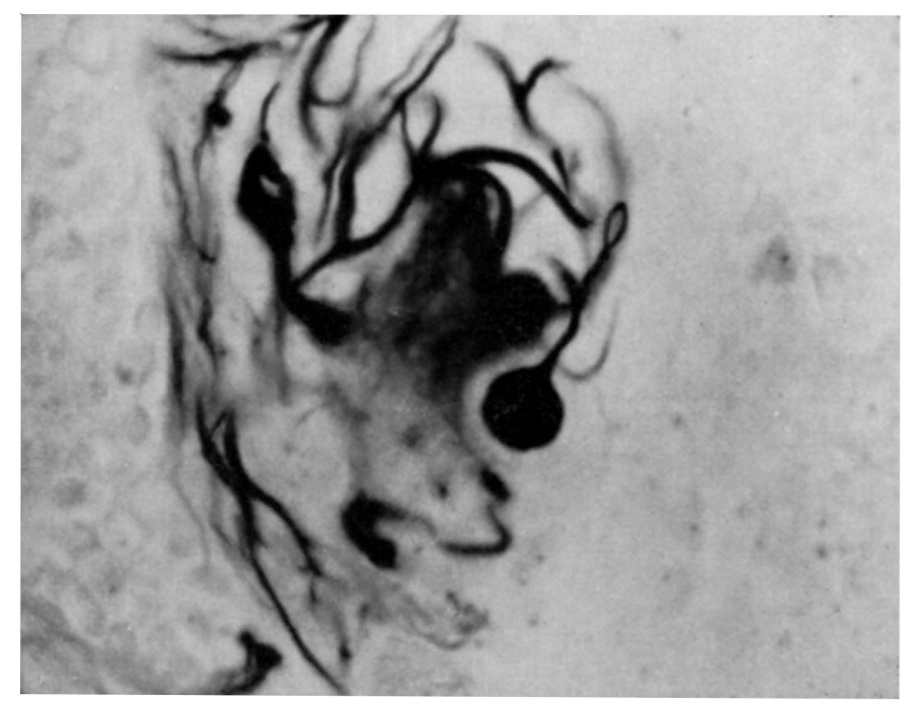

Fig. 6 -. Método de Artcla (450x). Arteriosclerose. Neurônii) com intensa degeneraçio retrátil e lipertrofia dos dendritos, eni intimo contacto com uma figura claviforme.

Arteta's method $(450 \mathrm{x})$. Arteriosclerosis. Neuron with intense. retractible degeneration and dendrite hypertrophy, in close conneciion with a claviform figure.

$\mathrm{Na}$ arteriosclerose notamos também as formações em bolas argênticas. Em um caso, a bola argêntica estava em relação com neurônio que sofria intensa degeneração retrátil (fig. 6), notando-se, em outro caso, que a bola argêntica se comunicava com o neurônio por intermédio de um prolongamento hipertrofiado (fig. 2). Herzog 18, 20 refere o achado de bolas argênticas na arteriosclerose. Eisendecher " $"$ que afirma serem as bolas argênticas de significado muito discutido, chama a atenção para a sua ausência nos casos de arteriosclerose juvenil.

Achúcarro já havia notado as relações existentes entre o aparecimento das bolas argênticas e a presença de um pigmento argentófilo no citoplasma das células ganglionares. Entretanto essas relações só foram confirmadas mais tarde, com os trabalhos experimentais da escola russa. Fedorow e Matwejewa ${ }^{13}$ descreveram, como primeiro sinal de alteração dos neurônios, a presença de uma argentofilia mais acentuada em uma fase (período de 
irritação) que é seguida pelo aparecimento de vacúolos e, ulteriormente, de uma substância granulosa; Fedorow ${ }^{12}$ descreveu a presença de grânulos que se coram pelo vermelho neutro. Esquemàticamente podemos dividir os pigmentos encontráveis nos neurônios simpáticos em dois tipos: uns que se impregnam pelos sais de prata, e outros que se não impregnam.

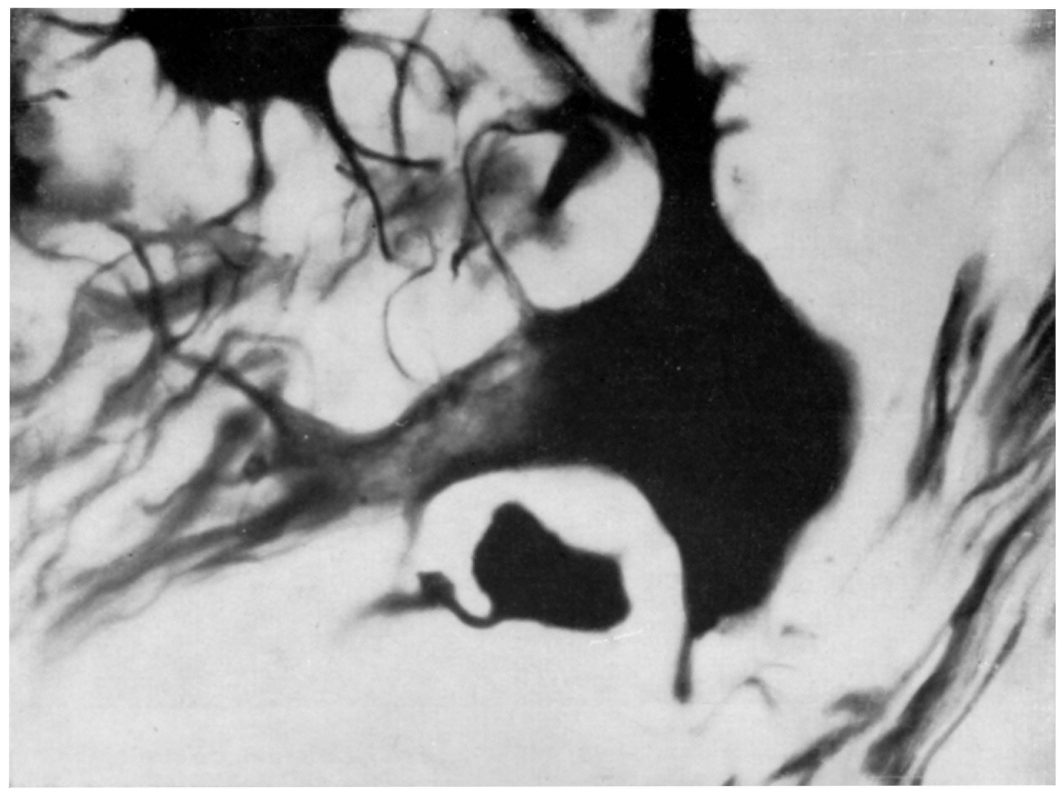

Fig. 7 - Método de Gros (450x). Úlcera trófica. Bula argêntica intracapsular em intimo contacto com um neurônio em retraçăo.

Gros' method $(456 \mathrm{x})$. Trophic ulcer. Intra-capsular argentic ball in close connection with a retracted neuron.

Em alguns casos de doenças vasculares periféricas, nos quais procurávamos estudar o comportamento do tecido conjuntivo, observamos, em cortes corados pelos tricrômicos de Gomori e de Goldner, a presença de um pigmento distribuido de maneira desordenada por todo o citoplasma celular, sob a forma de pequenas gôtas coradas em vermelho-laranja ou róseo carregado (fig. 9). Êste pigmento não existia em tôdas as células e sua quantidade variava de um caso para outro, mesmo quando se tratava de enfermidades idênticas. No mesmo corte onde notamos estas formações, verificamos também a presença de outro pigmento, amarelo escuro, que identificamos como sendo pigmento melânico. Nas impregnações pelcs sais de prata, observamos a presença de um pigmento intensamente corável, distribuindo-se em pequenos grânulos reunidos em determinadas zonas. Na vizinhança das células que apresentam êste último tipo de pigmento, notamos, freqüentemente, alterações dos prolongamentos, inclusive formações em bolas argênticas e ou- 
tros sinais de sofrimento. Nada podemos acrescentar em defınitivo com relação à presença do pigmento que vimos com as colorações de Gomori e de Goldner, pois a literatura disponivel trás poucos esclarecimentos; é bem pos. sivel que sejam idênticos aos corados pclo vermelho neutro por Fedorow. Pensamos que as causas que determinam seu aparecimento sejam as mesmas que favorecem o aparecimento das formaçōes em bolas argênticas, isto é, processos que determinam alterações do tipo proliferativo.

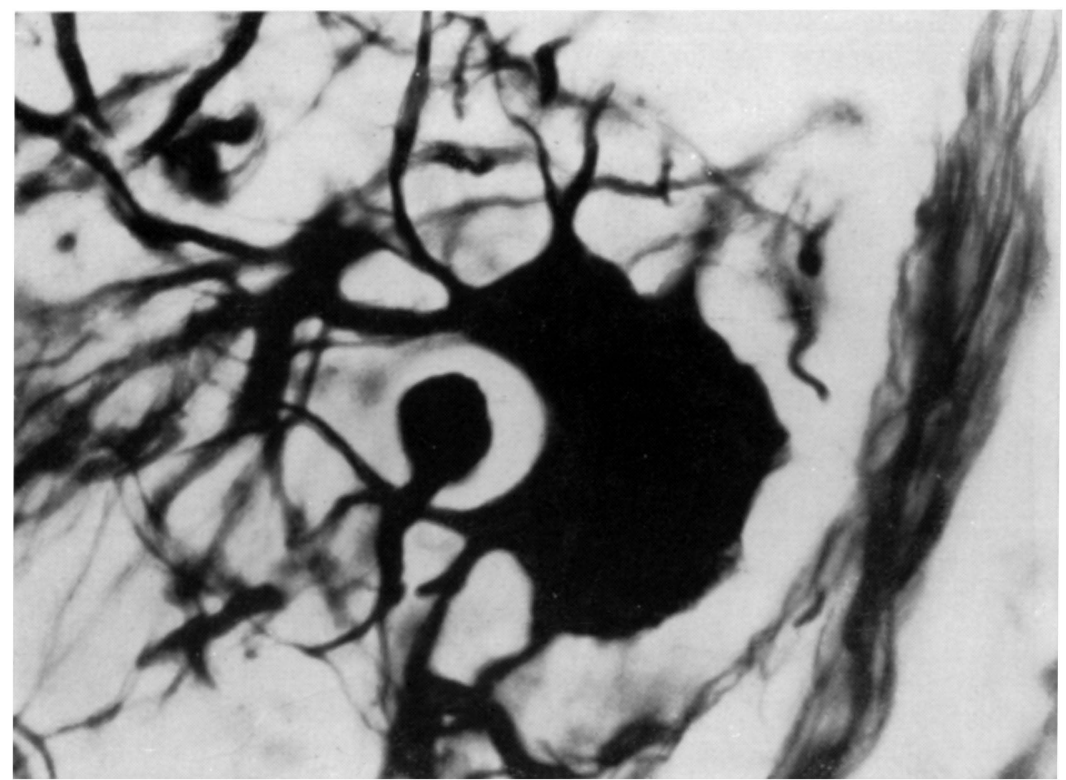

Fig. 8 - Método de Gros (450x). Moléstia de Raynaud. Figura claviforme no final de uma fibra pré-ganglionar, notando-se retraçio do neurónio no ponto cie cantacto entre ambas formacões.

Gros' method (450x). Raynaud's disease. Claviform figure at the end of a pre-ganglionary fiber; neuron retraction can be noticed between both formations.

Não se conhece ainda a significação exata das bolas argênticas, porém, é possível que elas estejam ligadas a uma hiperfunção do simpático por excitação; como prova disto temos a sua presença em muitos casos de transtornos circulatórios periféricos. Herzog ${ }^{2: 3}$ refere que, em parte, estas formações são devidas à precipitação de nitrato de prata em estruturas reticulares, como são as terminações nervosas. Em nossas preparações pudemos verificar que se trata de estruturas nervosas e não de artefatos de coloração. Segundo Emhart 11 poder-se-ia pensar que as bolas argênticas determinam interrupção da condução nervosa na sinapse entre a fibra pré-ganglionar e o neurônio. Contudo nem sempre as bolas argênticas determinam interrupção da sinapse, pois se algumas vêzes o neurônio em íntima relação com a refe- 
rida formaçāo, se apresenta intensamente lesado (figs. 2, 5 e 6), outras vêzes a alteração é discreta (fig. 4). As alteraçōes leves provàveimente são reversiveis, podendo os neurônios voltar a ser inteiramente normais. Em outros casos a lesão poderia ser primitiva do neurônio, alterando-se ulteriormente a fibra e aparecendo a formação em bola argêntica; como prova disto temos os trabalhos experimentais de Fedorow e Matwejewa 1:2 que determinaram inicialmente um "período de irritação" com duração de 2 a 7 dias (argentofilia acentuada e aparecimento de vacúolos), e ulteriormente, após 12 a 17 dias, uma "gelificação" dos discos terminais e das fibras pericelulares com intcnsa impregnação (formação de bolas argênticas).

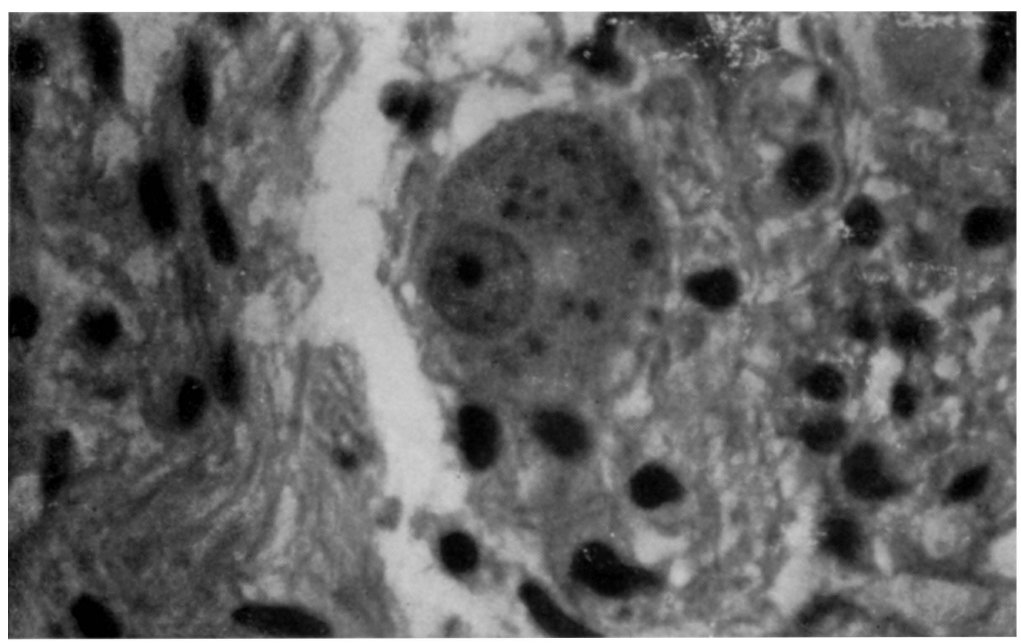

Fig. 9 - Método de Goldner (450x). Úlcera trófica. Neurônio intensamente pigmentado.

Goldner's inetinod (450x). Trophic ulcer. Intensely pigmented neuron.

Baseados na literatura e, principalmente, em nossas próprias observações, admitimos que as formações em bolas argênticas são patológicas. A produção das bolas argênticas, alteração proliferativa, é observada nas mais diversas enfermidades, principalmente nas doenças vasculares perıféricas, significando uma hiperfunção do simpático.

\section{RESUMO E CONCLUSÕES}

Foram estudados, histològicamente, gânglios simpáticos provenientes de 40 pacientes portadores de enfermidades variadas e 40 gânglıos tidos como normais, para pesquisar as formações $\mathrm{cm}$ bolas argênticas. As impregnaçōes foram feitas pelos métodos de Cajal, Arteta, Castro, Gros, Bielschowsky e Agduhr. Foi verificado que a presença de bolas argênticas é mais constante 
nas doenças circulatórias periféricas; nestas afecçōes, foi verificada, também, a presença de um pigmento corável pelos tricrômios de Gomori e de Goldner e que, possivelmente, tem o mesmo significado que os descritos por Fedorow ${ }^{12}$ corados pelo vermelho neutro; tais pigmentos foram relacionados com as formações em bolas argênticas, levando em consideração os trabalhos experimentais dos autores da escola russa. A presença das formações em bolas argênticas, tanto nos casos normais como nos patológicos, é atribuída a uma hiperfunção, por excitação, do simpático, por serem mais numerosas nos casos de transtornos periféricos. Foi observado que os neurônios em intimo contacto com as formaçōes em bolas argênticas, apresentam sempre alteraçōes que vão desde o grau mais leve (tumefação do soma celular, retificação dos prolongamentos, neurofibrilas mais fortemente impregnadas), até o mais grave (hiperplasia e hipertrofia dos dendritos, degeneração retrátil, degeneração pigmentar). Foi notado que as terminaçōes das fibras pré-ganglionares e as próprias fibras apresentam, muitas vêzes, alterações (hipertrofia, sinuosidade e grande poder de impregnação); as bolas argênticas foram observadas tanto no final dos dendritos como no das fibras pré-ganglionares. Foram encontradas formações de bolas argênticas em rosário, concluindo-se que $\epsilon$ las têm a mesma significação que as alterações claviformes. Conclui-se, finalmente, que as bolas argênticas são produtos patológicos.

\section{SUMMARY AND CONCLUSIONS}

The argentic ball formations of the sympathetic nervous system. lts signification.

Histologic studies of sympathetic ganglia from forty patients with different diseases and of forty normal ganglia were made in order to study the so-called "argentic balls" formations. Impregnations were made by the methods of Cajal, Arteta, Castro, Gros, Bielschowsky and Agdhur. It was demonstrated that "argentic balls" are more frequent in peripheric circulatory diseases; by Gomori and Goldner tricomes method's a pigment was also found; these pigments were related to argentic balls formations, according to experimental works of Russian authors. The presence of argentic balls in normal as well as in pathological cases is tied to hyperfunction of the sympathetic system. It was observed that neurons in close contact with argentic balls, always show alterations which range from the slight (tumefaction of cellular soma, retification of prolongations, strong impregnation of neurofibrils) to the serious (hyperplasia and hypertrophy of dendrites, retractible degeneration, pigmentary degeneration). Many times the terminal part of pre-ganglionary fibers and the fibers themselves present hypertrophy, sinuosity and great affinity for impregnation; argentic balls were observed at the ends of both the dendrites and the pre-ganglionary fibers. Rosary-like argentic balls formations were seen and considered as having the same. significance as the so-called claviform alterations. The author concludes that argentic balls are pathological productions. 


\section{REFERENCIAS}

1. ACHUCARRO, N. - Alteraciones del ganglio cervical superior simpático en algunas enfermedades mentales. Trab. Lab. Invest. Biol. Univ. Madrid, 12:55-66, 1914. 2. BULLON RAMIREZ, A. - Contribución al conocimiento de la citoarquitectonia del plexo de Auerbach del recto. Trab. Inst. Cajal Invest. Biol., 39:253-272, 1947. 3. BULLON RAMIREZ, A.; LAMAS LOPEZ, F. - Regeneración de la sinap is después de la vagotomia cervical, en el plexo de Auerbach del esofago y estomago. Trab. Inst. Cajal Invest. Biol., 41:277-307, 1949. 4. CAJAL, S. R. — Las células del gran simpátíco del hombre adulto. Trab. Lab. Invest. Biol. Univ. Madrid, 4:79-104, 1906. 5. CASTRO, F. de - Estudios sobre el ganglio sensitivo del hombre en estad( normal y patológico. Trab. Lab. Invest. Biol. Univ. Madrid, 19:241-340, 1922. 6. CASTRO, F. de - Evolución de los ganglios simpáticos prevertebrales. Conexiones y citoarquitectonia de algunos grupos de ganglios, en el niño y hombre adulto. Trab. Lab. Invest. Biol. Univ. Madrid, 20:113-208, 1923. 7. CASTRO, F. de - Note sur la régénéracion fonctionnelle hétérogénétique dans les anastomoses des nerfs pneumogastrique et hypoglosse avec le sympathique cervical. Trav. Lab. Recher. Biol. Univ. Madrid, 29:397-416, 1934. 8. CASTRO, F. de - Sur la régénération fonctionnelle dans le sympathique (anastomoses croisées avec des nerfs de type iso et hétéromorphes). Une référence spéciale sur la constitution des synapses. Trav. Lab. Recher. Biol. Univ. Madrid, 31:271-345, 1936-37. 9. CASTRO, F. de - Modelación de un arco reflejo en el simpático, uniéndolo con la raiz aferente central del vago; nuevas ideas sobre la sinapsis. Trab. Inst. Cajal Invest. Biol., 34:217-301, 1942.10. EISENDOCHER, C. M. - Relaciones anátomo-patológicas entre la arterioesclerose aórtica y los ganglios simpáticos. Bol. Soc. Biol. de Concepción (Chile), 11:45-65, 1937.11. EMHART, O. - Participación de los ganglios nodoso y yugular del vágo y de sus núcleos centrales en la tuberculosis pulmonar-laringea y en la úlcera gástrica. Bol. Soc. Biol. de Concepción (Chiie), 16:45-58, 1942. 12. FEDOROW, B. G. - Essai de l'étude intravitale des cellules nerveuses et des connexions interneuronales dans le système nerveux autonome. Trav. Lab. Recher. Biol. Univ. Madrid, 30:403-434, 1935. 13. FEDOROW, B. G.; MATWEJEWA, S. J. - La structure des connexions interneuronales dans le système nerveux autonome de la grenoiu!le. Trav. Lab. Recher. Biol. Univ. Madrid, 30:379-401, 1935. 14. FEDOROW, B. G.; MATWEJEWA, S. J. - Recherches sur l'histologie comparée du système nerveux autonome. Trav. Lab. Recher. Biol. Univ. Madrid, 31:203-228, 1936-37. 15. FERNANDEZ, J. --. Morfopatología de los Ganglios Simpáticos Lombares. Tesis doctoral. Madrid, 1954. 16. FERNANDEZ, J. - Morfopatologia dos gânglios simpáticos lombares na tromboangeite obliterante. Rev. Ass. Med. Brasil., 2:237-242, 1956. 17. FERNANDEZ, J. - Histopatologia do gânglio estrelado na tuberculose pulmonar. Arq. Neuro-Psiquiat., 15:1-14, 1957.18. HERZOG, E. - Histologia patológica del sistema nervioso vegetativo. In L. B. Muller - Sistema Nervioso Vegetativo. Ed. Labor, Madrid, págs. 894-970. 19. HERZOG, E. - El fenómeno de las bolas argentófilas en el sistema nervioso vegetativo periférico. Bol. Soc. Biol. de Concepción (Ch:le), 16:37-44, 1942. 20. HERzOG, E. -Die Pathologie der peripheren vegetativen Ganglien. Verhand. der Deutsch. Gesellschft für Pathol., 34 Tag. in Wiesbaden v. 20-23, April, 1950. 21. HERZOG, E. - Progresos de la patología morfológica del sistema nervioso vegetativo periférico. Bol. Soc. Biol. de Concepción (Chile), 27:77-85, 1952. 22. HERZOG, E. — Histopathologie des vegetativen Nervensystems. In Handbuch der Speziellen Pathologischen Anatomie und Histologie. Erkrankungen des Peripheren und der Vegetativen Nervensystems. Springer Verlag, Berlim, 1955, págs. 356 a 542. 23. HERZOG, E.; MARTINEZ, A. Alteraciones patológicas de los ganglios vegetativos intra y extracardiacos. Rev. Sudamer. Morfolog., 2:1-22, 1944. 24. LASOWSKY, J. M. - Normale und pathologische Histologie der Herzganglien des Menschen. Wirch. Arch., 279:464-485, 1930. 25. LAWRENTIEW, B. I.; FILATOWA, A. G. - Histopathologie du nerf laryngé inférieur et de ses terminaisons au cours de la laryngite tuberculeuse. Trav. Lab. Recher. Biol. Univ. Madrid, 29:318-319, 1934. 26. LAWRENTIEW, B. I.; LASOWSKY, I. M. - Über die Reizerscheinungen in autonomen Nervensystem (Die Natur des sogen. Kugelphänomens). Z. Neurol., 131:585-601, 1931. 27. MARINESCO, G. - La 
Cellule Nerveuse. Tome II, chap. XXIV. Octave Doin et Fils, Édit., Paris, 1909. 28. MELO, R. M. - Histopatología del ganglio nodoso del vago. Bol. Soc. Biol. de Concepción (Chile), 13:5-22, 1939. 29. ORELLANA, E. S. - El pigmento del simpático periférico. Bol. Soc. Biol. de Concepción (Chile), 12:5-19, 1938. 30. SCHAFFER, C. - Contributions à l'histopathologie des ganglions rachidiens dans I'idiotie amaurotique (type Tay-Sachs). Trab. Lab. Invest. Biol. Univ. Madrid, 20:81-92, 1923.

Nota do autor - Este trabalho estava sendo impresso quando recebemos do Prof. Stohr uma separata de trabalho de J. Sarter (Morphologische Veränderungen an den Ganglien des Sympathischen Grenzstranges und Vagus bei Mycosis fungoides - Deutsche Zeitschrift f. Nervenheilk., 175:471-487, 1957), no qual encontramos referências às produções em bolas argenticas e, o que é mais importante, a um pigmento, no citoplasma de alguns neurônios, que se cora pelo método de Gomori, que seria, segundo Sarter, um produto metabólico patológico, faltando provas para que seja considerado como a evidência de neuro-secreção. Éste pigmento é idêntico ao que descrevemos e que conseguimos corar com os métodos de Gomori e de Goldner.

Fundaçăo Hospitalar octavio Mangabeira - Departamento de Anatomia Patológica - Salvador, Bahia, Brasil. 